\title{
Biometric and statistical investigations on the cnidoma of the genus Hydra (Cnidaria, Hydrozoa)
}

\author{
Maria I. Deserti ${ }^{1} \&$ Mauricio O. Zamponi ${ }^{1,2}$
}

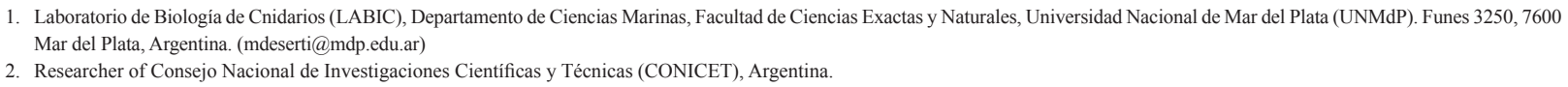

RESUMEN. Investigaciones biométricas y estadísticas en el cnidoma del género Hydra (Cnidaria, Hydrozoa). El presente estudio utiliza los nematocistos como fuente de información biométrica para llevar a cabo comparaciones entre las especies Hydra vulgaris Pallas, 1766, Hydra vulgaris pedunculata Deserti et al., 2011 y Hydra pseudoligactis (Hyman, 1931). La utilización de dicha herramienta nos permitió realizar comparaciones estadísticas y sumar los resultados obtenidos a la identificación clásica de especímenes pertenecientes a diferentes grupos clasificatorios. Utilizando entonces la biometría de los nematocistos, se hallaron diferencias estadísticamente significativas al comparar especies distintas, individuos de cada especie y tipos de nematocistos. Se observo variación del tamaño de las cápsulas de los nematocistos atrico isorriza y holotrico isorriza para la especie $H$. vulgaris en relación al tamaño de la columna del ejemplar.

PALABRAS-CLAVE. Nematocistos, biometría, análisis estadísticos.

\begin{abstract}
This paper deals about the nematocysts like a source of biometric information for comparison between the species Hydra vulgaris Pallas, 1766, Hydra vulgaris pedunculata Deserti et al., 2011 and Hydra pseudoligactis (Hyman, 1931). This biometric tool lets us carry out statistical comparisons and adding these results to the identification of specimens from different classificatory groups. In this particular study, we obtained significant differences between species, individuals of each species and nematocysts type when compared the biometry of its nematocysts. Another result was the variation in of particular nematocysts, like atrichous isorhiza and holotrichous isorhiza for the species $H$. vulgaris in relation to the column size.
\end{abstract}

KEYWORDS. Nematocysts, biometry, statistical analysis.

The fundamental characteristic of members of the Phylum Cnidaria is the possession of stinging cells called cnidae (MARISCAL, 1974). These cnidocysts are one of the most complex and enigmatic eukaryotic cells, are present in all members of the phylum and as such, are important diagnostic feature of them (Chintiroglou et al., 1996). Since CARLgRen (1900) the description of nematocysts has drawn attention of many researchers for a long time. An inventory of all the cnidae types present in the tissues of a cnidarian is known as its cnidoma (WeILL, 1926) but no information on cnidae size is implicit in this definition (Williams, 1998).

In some cases, the form, proportions and relative sizes of the nematocysts were the guide more simple and reliable for the separation of the species; today we know that the entire complex of characters shown by a form must be taken into account (FORREST, 1963); many times, this characteristics varies considerably and depending on the stage of development of the nematocysts (WeILL, 1934). In Hydra hymanae Hadley \& Forrest, 1949 and Hydra americana Hyman, 1929, for example, the nematocysts are closely similar, but the hydras differ importantly in other aspects like relative length of tentacles and sexual characters (FORREST, 1963).

The biometry of the cnidae can contribute significantly to the classification of Cnidaria (PANAGioTiS \& Chintiroglou, 1997). Östman et al. (1987) revealed a considerable variation in cnidoma biometry for hydrozoan populations from a variety of Mediterranean and Scandinavian shores. ITô (1951) found statistically significant differences in shapes and sizes of stenoteles and holotrichous isorhiza from populations of Hydra robusta
(ITô, 1947) collected from widely separated localities, but this differences was not present for populations located in habitats more nearby (FORREST, 1963).

This polyp has been used in many different fields of biology, yet the individual species themselves have been difficult to define (MARTINEZ et al., 2010) and the taxonomy and phylogenetic relationships of the species within the genus have always been uncertain (EwER, 1948).

The systematic implication of nematocysts is clear, all cnidarians and only the cnidarians produced them (Fautin, 2009).

In the genus Hydra, the biometric and statistical investigations on the cnidoma are scarcely studied. This work explores the systematic possibilities contained in the cnidae of this genus and the implications of these results in their taxonomy.

\section{MATERIAL AND METHODS}

Three species of genus Hydra were collected and used to carry out this study: Hydra vulgaris Pallas, 1766 and Hydra pseudoligactis (Hyman, 1931) from Nahuel Rucá ( $37^{\circ} 40^{\prime} \mathrm{S}, 57^{\circ} 23^{\prime} \mathrm{W}$, Buenos Aires, Argentina) in September 16, December 11 of 2009, respectively and Hydra vulgaris pedunculata Deserti et al., 2011 from

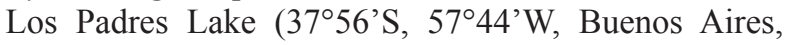
Argentina) in May 7 of 2009.

For each species, ten specimens were studied and the following morphological variables were measured: height of column (HC) and the ratios $\mathrm{HC} / \mathrm{WC}$ (height of column/width of column). 
In squash preparations, thirty undischarged capsules of each type of nematocysts were measured and their length (L) and width (W) were recorded (Fig. 1). The ratios $(\mathrm{L} / \mathrm{W})$ were calculated because are considered a significant parameter of cnidae biometry (THOMASON, 1989). This procedure was carried out for each specimen of hydra collected. All measurements were taken using an optical microscope with $10 \times 100$ objectives, equipped with a micrometer ocular 10/100.

Fifteen undischarged capsules for each nematocyst type were used for comparative analysis of the nematocyst biometry between species, individuals of each species and nematocyst type. These comparisons were made employing the PERMANOVA test using PRIMER 6.0 (CLARCK \& GoRLEY, 2006) statistic program for Windows. The PERMANOVA test grouped the biometric data in three factors: species, individual

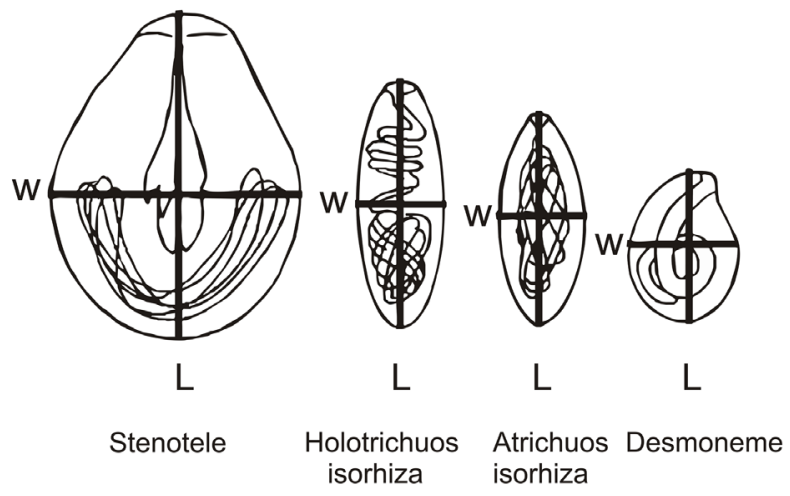

Fig. 1. Diagram showing the length (L) and width (W) of the capsules of each nematocyst type (modified from CAMPBELL, 1983). and nematocyst type (Fig. 2). This test use 9.999 permutations and the measure of similitude used was the Euclidean distance.

Relationships between L/W with $\mathrm{HC}$ and $\mathrm{HC} / \mathrm{WC}$ were determined with Spearman's rank correlation test. This test is frequently used for small data sets and was carried out with the statistic program SIGMA-STAT 3.0 for Windows.

\section{RESULTS}

Description data. Mean, standard deviation and range for the morphological variables $\mathrm{HC}$ and $\mathrm{HC} / \mathrm{WC}$ are shown in table I and for length, width and biometry parameter of nematocysts in table II.

Three factors PERMANOVA test. Comparisons of nematocyst biometry within species showed significant differences (Tab. III). Pairs wise $H$. vulgaris- $H$. pseudoligactis and $H$. vulgaris pedunculata- $H$. pseudoligactis showed significant differences in the biometry of their nematocysts ( $\mathrm{p}$-value $=0.0016$ and 0.0134 respectively); pair wise $H$. vulgaris- $H$. vulgaris pedunculata has not significant differences $(\mathrm{p}$-value $=$ 0.7251 ).

Between individuals of each species, nematocyst biometry did not have significant differences (Tab. III). Comparisons of the biometry of each type of nematocyst showed significant differences (Tab. III).

When the "individual" factor is eliminated, have not significant differences between species, but the biometry within nematocyst types until showed significant differences (Tab. IV).

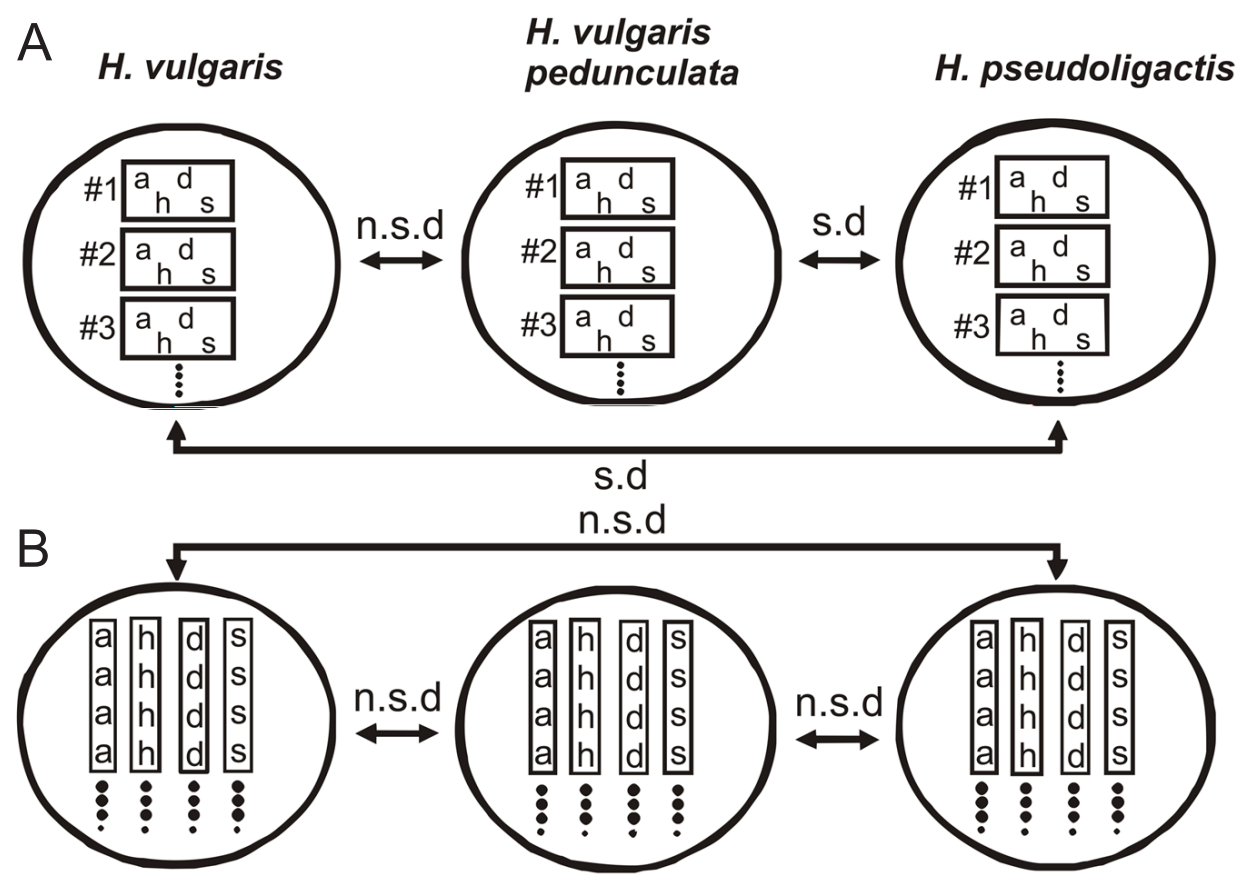

Fig. 2. Diagram with the three factors under which the biometric measures of the nematocysts are grouped (A) and when the "individual" factor it is eliminated (B) (\#, individuals; a, atrichous isorhiza; h, holotrichous isorhiza; d, desmoneme; s, stenotele; n.s.d, not significantly different; s.d, significantly different). 
Spearman's rank correlation test. Correlations between nematocyst biometry with $\mathrm{HC}$ and $\mathrm{HC} / \mathrm{WC}$ for $H$. vulgaris pedunculata, $H$. pseudoligactis and $H$. vulgaris are given in table $\mathrm{V}$.

$H$. vulgaris was the unique species that showed positive correlation for atrichous isorhiza with $\mathrm{HC}$ and $\mathrm{HC} / \mathrm{WC}$, and negative correlation for holotrichous isorhiza with $\mathrm{HC}$ and $\mathrm{HC} / \mathrm{WC}(\mathrm{p}<0.05)$. Both reminder species has not correlation between nematocyst biometric with morphological variables.

Tab I. Morphological variables in 10 individuals for the three taxa of Hydra studied (HC, height of column; HC/WC, height of column/width of column; sd, standard deviation).

\begin{tabular}{lccc}
\hline Species & Morphological variables & Mean \pm sd & Range \\
\hline H. vulgaris pedunculata & $\mathrm{HC}$ & $6.3384 \pm 2.68$ & $2.28-9.88$ \\
& $\mathrm{HC} / \mathrm{WC}$ & $7.2774 \pm 2.75$ & $5.00-13.00$ \\
H. pseudoligactis & $\mathrm{HC}$ & $3.9902 \pm 1.17$ & $2.12-5.34$ \\
& $\mathrm{HC} / \mathrm{WC}$ & $6.0426 \pm 2.50$ & $3.14-11.6$ \\
H. vulgaris & $\mathrm{HC}$ & $3.8304 \pm 0.60$ & $2.74-4.41$ \\
& $\mathrm{HC} / \mathrm{WC}$ & $8.9800 \pm 3.79$ & $5.40-14.50$ \\
\hline
\end{tabular}

Tab. II. Measurements of thirty undischarged capsules for each type of nematocysts for the 10 individuals of the three taxa of Hydra studied (NT, nematocyst type; S, stenotele; D, desmoneme; H, holotrichous isorhiza; A, atrichous isorhiza; sd, standard deviation; L/W (length/width), biometric parameter).

\begin{tabular}{lcccccccccc}
\hline & NT & \multicolumn{3}{c}{ Length $(\mu \mathrm{m})$} & \multicolumn{3}{c}{ Width $(\mu \mathrm{m})$} & \multicolumn{3}{c}{$\mathrm{L} / \mathrm{W}(\mu \mathrm{m})$} \\
\hline Species & & mean & $\mathrm{sd}$ & range & mean & sd & range & mean & sd & range \\
\hline H. vulgaris & $\mathrm{S}$ & 14.63 & 1.93 & $10.00-18.00$ & 11.48 & 1.78 & $6.00-15.0$ & 1.28 & 0.12 & $1.07-1,71$ \\
pedunculata & $\mathrm{D}$ & 8.50 & 1.11 & $6.00-12.00$ & 5.76 & 0.73 & $4.00-7.00$ & 1.44 & 0.26 & $0.78-2,20$ \\
& $\mathrm{H}$ & 11.96 & 1.15 & $9.00-14.00$ & 5.38 & 0.70 & $4.00-7.00$ & 2.24 & 0.28 & $1.71-2,80$ \\
& $\mathrm{~A}$ & 8.20 & 1.24 & $5.00-10.00$ & 4.74 & 0.71 & $3.00-7.00$ & 1.53 & 0.23 & $1.20-2,50$ \\
\hline H. & $\mathrm{S}$ & 14.11 & 2.22 & $10.00-20.00$ & 11.46 & 1.92 & $7.00-16.0$ & 1.23 & 0.08 & $1.06-1,50$ \\
pseudoligactis & $\mathrm{D}$ & 6.76 & 0.65 & $6.00-8.00$ & 4.91 & 0.63 & $4.00-6.00$ & 1.39 & 0.19 & $1.00-2,00$ \\
& $\mathrm{H}$ & 11.04 & 0.97 & $8.00-14.00$ & 4.91 & 0.49 & $4.00-6.00$ & 2.26 & 0.25 & $1.66-3,00$ \\
& $\mathrm{~A}$ & 8.49 & 0.87 & $7.00-11.00$ & 4.26 & 0.54 & $3.00-5.00$ & 2.01 & 0.22 & $1.40-2,66$ \\
\hline H. vulgaris & $\mathrm{S}$ & 15.68 & 2.03 & $13.00-19.00$ & 13.17 & 1.65 & $10.0-16.0$ & 1.19 & 0.16 & $0.86-1,90$ \\
& $\mathrm{D}$ & 7.48 & 0.50 & $7.00-8.00$ & 5.23 & 0.66 & $4.00-6.00$ & 1.45 & 0.21 & $1.16-2,00$ \\
& $\mathrm{H}$ & 11.08 & 0.74 & $10.00-12.00$ & 4.58 & 0.49 & $4.00-5.00$ & 2.44 & 0.29 & $2.00-3,00$ \\
& $\mathrm{~A}$ & 7.38 & 0.56 & $7.00-8.00$ & 4.37 & 0.48 & $4.00-5.00$ & 1.70 & 0.21 & $1.20-2,00$ \\
\hline
\end{tabular}

Tab. III. Comparison of the biometry of the nematocysts between species, individuals of each Hydra species studied and nematocysts types (Sp, species; Ind, individuals; Nem, nematocysts type; df, degrees of freedom; SS, sum of squaring; MS, squared average). Bold numbers: statistically significant $(\mathrm{p}<0.05)$.

\begin{tabular}{lccccc}
\hline \multicolumn{1}{c}{ Source } & df & SS & MS & Pseudo-F & P-value \\
\hline Species & 2 & 2.6232 & 1.3116 & 5.3382 & $\mathbf{0 . 0 1 2 6}$ \\
Ind (Sp) & 27 & 6.4209 & 0.23781 & 6.56 & 1 \\
Nem (Ind (Sp)) & 89 & 322.86 & 3.6276 & 81.923 & $\mathbf{0 . 0 0 0 1}$
\end{tabular}

Tab. IV. Comparison of the biometry of the nematocysts between Hydra species studied when the "individual" factor it is eliminated (Pooled, biometric parameter for each type of nematocyst (without "individual" factor); df, degrees of freedom; SS, sum of squaring; MS, squared average). Bold numbers: statistically significant $(\mathrm{p}<0.05)$.

\begin{tabular}{lrrrrr}
\hline Source & \multicolumn{1}{c}{ df } & \multicolumn{1}{c}{ SS } & \multicolumn{1}{c}{ MS } & Pseudo-F & P-value \\
\hline Species & 2 & 2.6232 & 1.3116 & 0.46258 & 0.6247 \\
Pooled & 116 & 328.95 & 2.8358 & 64.04 & $\mathbf{0 . 0 0 0 1}$ \\
\hline
\end{tabular}

Tab. V. Spearman's rank correlation coefficient between morphological variables and the biometry of the nematocysts of Hydra vulgaris pedunculata Deserti et al., 2011, Hydra pseudoligactis (Hyman, 1931) and Hydra vulgaris Pallas, 1766 (L/W, length/width; HC, height of column; HC/ WC, height of column/width of column). Bold numbers: statistically significant $(\mathrm{p}<0.05)$.

\begin{tabular}{|c|c|c|c|c|c|}
\hline \multicolumn{6}{|c|}{ Biometric parameter $(\mathrm{L} / \mathrm{W})$} \\
\hline \multicolumn{2}{|c|}{ Hydra vulgaris pedunculata } & Desmoneme & Atricho & Holotricho & Stenotele \\
\hline \multirow[t]{2}{*}{$\mathrm{HC}$} & Correlation Coef. & 0.356 & 0.418 & 0.578 & 0.591 \\
\hline & P-value & 0.270 & 0.188 & 0.0555 & 0.051 \\
\hline \multirow[t]{2}{*}{$\mathrm{HC} / \mathrm{WC}$} & Correlation Coef. & 0.237 & 0.350 & 0.40 & -0.474 \\
\hline & P-value & 0.467 & 0.270 & 0.21 & 0.132 \\
\hline \multicolumn{6}{|c|}{ Hydra pseudoligactis } \\
\hline \multirow[t]{2}{*}{$\mathrm{HC}$} & Correlation Coef. & -0.058 & -0.0909 & 0.103 & 0.241 \\
\hline & P-value & 0.781 & 0.662 & 0.623 & 0.243 \\
\hline \multirow[t]{2}{*}{$\mathrm{HC} / \mathrm{WC}$} & Correlation Coef. & 0.316 & -0.0543 & -0.374 & 0.289 \\
\hline & P-value & 0.122 & 0.792 & 0.065 & 0.159 \\
\hline \multicolumn{6}{|c|}{ Hydra vulgaris } \\
\hline \multirow[t]{2}{*}{$\mathrm{HC}$} & Correlation Coef. & 0.393 & -0.325 & -0.390 & 0.106 \\
\hline & P-value & 0.034 & 0.0845 & 0.036 & 0.583 \\
\hline \multirow[t]{2}{*}{$\mathrm{HC} / \mathrm{WC}$} & Correlation Coef. & 0.574 & -0.228 & -0.417 & 0.209 \\
\hline & P-value & 0.0012 & 0.233 & 0.024 & 0.274 \\
\hline
\end{tabular}




\section{DISCUSSION}

Many authors have studied quantitative aspects of nematocysts belonging to different cnidarian taxa (Weill, 1934; Mariscal, 1974; Östman et al., 1987; Thomason, 1989; Chintiroglou et al., 1996; Panagiotis \& Chintiroglou, 1997; Williams, 1998; Acuña et al., 2003; Fautin, 2009), and most of them have applied traditional statistical tools, such as parametric and nonparametric tests.

The intense interest that cnidae have stimulated derives from their being the most complex intracellular secretion known, from the unique ability of cnidarians to secrete them, from their microstructural beauty, and increasingly from their biomedical importance (SHICK, 1991).

This study about the biometry of the nematocysts on the genus Hydra showed many results to be analyzed. On a first step, the results listed in table III let us considered the nematocysts like an entities well definite because the biometric parameters are significant different between the four types.

The three analyzed species are significant different between them from statistical point of view and this result is another valid argument to hold that the three species are taxonomically separated. This statistical procedure could be joining to the classical taxonomic diagnosis. The systematic of this group is some times difficult "per se" and in many cases depends of personal criteria of the investigators (MARTINEZ et al., 2010).

All this biometric data lets to the authors confirm that Hydra vulgaris and $H$. pseudoligactis are significant different between them, so this point of view lets confirm that these species belonging to different groups; the specimens of $H$. pseudoligactis and $H$. vulgaris pedunculata are significant different too and holding the criteria above mentioned, both species belonging to different groups.

The comparison between $H$. vulgaris and $H$. vulgaris pedunculata has not significant differences; with the same criteria used in the previous cases, this result is according with the fact of these species belonging to the same group (vulgaris group) and the differences observed between them is only the presence of stalk near the foot in the subspecies. Based on this result we could say that, in both species, the nematocyst retained the same biometric characteristics.

The biometry of nematocysts between individuals of the same species has not significant differences, so it is a valid result to confirm specific ownership of each individual let us differenced between distinct species. But this result is opposite to the obtained when the "individual" factor is eliminated in the statistical tests (when the measurements of nematocysts only are grouped under "species" factor); here, the significant differences between species does not exist (Fig. 2; Tab. IV). Under this conditions, was tested the biometry between nematocysts type and the results obtained was the existence of significant differences for them. This result let us confirmed the strong identity of the nematocysts on relation of their biometry.

This global result is very important to design the sampling and take out of measurement of nematocyst. This analysis makes clear the importance of assigning the sizes of the nematocysts to each individual separately like a previous statistical procedure.

A peculiar data was the relationships between two types of nematocysts with morphological variables for $H$. vulgaris. For them the atrichous isorhiza shown a positive correlation with the column size; it increases when the column grows up. But the holotrichous isorhiza shown a negative correlation; it reduces under the same condition (Tab. VIII). Their stenoteles and desmonemes are independent of the column size. This result was not seen in $H$. pseudoligactis and $H$. vulgaris pedunculata; for them, the nematocysts biometry did not have relationships with the column size. The variation observed in H. vulgaris can to be attributing to some metabolic factors inherent to the specimen or perhaps to the influence of some environmental unknown factor. To know for certain these results, are necessary more studies about this point maybe in another species or with more measurements of the nematocysts. Perhaps, would be appropriate compare the biometric parameters of cnidocysts with measures that better reflect the size of the body, like the dry weight of specimens.

This study contributed to amplify and clarify the role of nematocysts in the taxonomy of this genus; is an approximation on the use of the nematocyst biometry like measure for statistical comparisons.

Acknowledgements. The authors thanks Lic. Veronica Taglioretti (Departamento de Biología, UNMdP) for statistical treatment.

\section{REFERENCES}

Acuña, F. H.; Excoffon, A. C.; Zamponi, M. O. \& Ricci, L. 2003. Importance of nematocysts in taxonomy of acontiarian sea anemones (Cnidaria, Actiniaria): a statistical comparative study. Zoologischer Anzeiger 242:75-81.

Campbell, R. D. 1983. Identifying Hydra species. In: Lenhoff, H. M. ed. Hydra: Research Methods. New York, Plenum Press. p.19-28.

Carlgren, O. 1900. Ostafrikanische Actinien. Mitteilungen aus dem Natuhistorischen Museum in Hamburg 17:1-24.

Chintiroglou, C. C.; Doumenec, D.; Le Renard, J.; Foubert, A. \& Kolyva MachaiRa, F. 1996. Classification of cnidarian nematocysts using multivariate and digital image analysis. Bios 4:123-135.

Clarck, K. R.; Gorley, R. N. 2006. Primer v6: Online free demo version. PRIMER-E. Plymouth. Available in: <http://www.primer-e. com/demo/demo.htm > Accessed on: 02.11.2010.

EwER; R. F. 1948. A review of the Hydridae and two new species of Hydra from Natal. Proceedings of the Zoological Society of London 118:226-244.

Fautin, D. G. 2009. Structural diversity, systematics, and evolution of cnidae. Toxicon 54:1054-1064.

ForRest, H. 1963. Taxonomic studies on the hydras of North America. VIII. Description of two new species, with new records and a key to the North American hydras. Transactions of the American Microscopical Society (82)1:1-17. 
ITô, T. 1947. On a new species of fresh-water polyp from Japan. Science Reports of Tohoku University, Fourth Series, Biology 18:1-5.

. 1951. Local and seasonal variations of the nematocysts in Pelmatohydra robusta Itô (Studies on the nematocysts of the fresh-water polyp. No. III). Memoires Ehime University, Section 2, 1:69-80.

Mariscal, R. N. 1974. Nematocysts. In: Muscatine, L. \& Lenhoff, H. $\mathrm{M}$. eds. Coelenterate Biology: reviews and new perspectives. New York, Academic Press. p.129-178.

Martinez, D. E.; Iñiguez, A. R.; Percell, K. M.; Willner, J. B.; Signorovitch, J. \& Campbell, R. D. 2010. Phylogeny and biogeography of Hydra (Cnidaria: Hydridae) using mitochondrial and nuclear DNA sequences. Molecular Phylogenetics and Evolution 57:403-410.

Östman, C.; Piraino, S. \& Roca, I. 1987. Nematocyst comparisons between some Mediterranean and Scandinavian Campanulariids (Cnidaria, Hydrozoa). In: Bouillion, J.; Boero, F.; Cicognat, F. \& Cornelius, P. F. S. eds. Modern trends in the systematic zoology and evolution of hydroids and hydromedusae. Oxford, Clarendon Press. p.299-310.
Panagiotis, K. \& Chintiroglou, C. C. 1997. Biometric investigations of the cnidae of the Rustica-color variety of the sea anemone Anemia viridis (Förskal, 1775). Israel Journal of Zoology 43:385-390.

Shick, J. M. 1991. A Functional Biology of Sea Anemones. London, Chapman \& Hall. 424p.

Thomason, C. J. 1989. The allometry of nematocyst. In: Hessinger, D. A. \& Lenhoff, H. M. eds. Symposium on the Biology of Nematocysts. San Diego, University of California. p.575588.

Weill, R. 1926. Existence, chez certains Coelentérés, d'un cnidome spécifique, caractéristique de l'état larvaire. L'interprétation des monocnidomes. Bulletin de la Société Zoologique de France 51:254-260.

1934. Contribution a l'étude des Cnidaires et de leurs nématocystes. II: Valeur taxonomique du cnidome. Travaux de la Station Zoologique de Wimereux 10/11:1-701.

Williams, R. B. 1998. Measurements of cnidae from sea anemones (Cnidaria; Actiniaria), II: further studies of differences amongst sample means and their taxonomic relevance. Scientia Marina 62(4):361-372. 